\title{
COMMUNICATING CLIMATE CHANGE IN AFRICA THROUGH THE THEATRE FOR DEVELOPMENT PROCESS \\ NDA, U.S. ${ }^{1}$ and ${ }^{*}$ EKONG, F.U. ${ }^{2}$ \\ http://dx.doi.org/10.4314/ejesm.v5i4.S1
}

Received 7th July 2012; accepted 7th September 2012

\begin{abstract}
The reality of climate change has started dawning on various parts of the world. The depletion of the ozone layer through over-heating of the atmosphere, actions and inactions of humans, has resulted in the thawing of the ice at the polar regions, which has caused the overflow of oceanic waters leading to massive floods in hitherto dry places and causing destruction of lives of persons and animals, infrastructure and the disruption of services essential for human existence and continuity. Such has been the effect of climate change that global and local measures need to be enunciated, agreed upon and implemented, in the bid to save the planet earth. These measures can only succeed if the humans are made to appreciate the gravity of the situation. The understanding is that humans need to be sensitized and people mobilized in a mass effort to reverse the trend. And the theatre for development methodology is recommended as a most dependable model of communication and mass mobilization process. And as the least of the continents in the technology drive, Africa presents itself as the most vulnerable in the event of a global disaster. This paper examines this issue and proposes how the theatre for development model of communication could be utilized in sensitizing the populace on the danger it portends. The enunciations shall also be influenced by the outcome of a practical theatre for development activity embarked upon by these researchers as lecturers in theatre arts and environmental planning.
\end{abstract}

Keywords: Climate change, Environment, Communication, Development process, Theatre arts, Africa

\section{Introduction}

The past decade has witnessed deterioration in the climatic situation of the world. The call for responsible consumption of the resources of nature and a safer handling of the globe by its human constituents was erroneously viewed by some, especially in the developing world, as a western ploy to dissuade them from exploiting their natural resources and the bid by the west to sell their products.

The various conferences on the environment have been global efforts to focus attention of people on the general problem of environmental degradation and the danger it portends for humanity. These Conferences have all striven to inculcate in citizens of the world the need to keep the global environment continuously safe for human habitation and continuity. The Bruntland Commission (1987), an international blueprint on environmental responsibility, was proposed and accepted by over 100 countries, though some of them are yet to fully ratify its provisions.

Apart from these efforts at the global level, local seminars and workshops have been held in various countries and their component regions and states, to popularize the message of safer environment. For instance Nda (2007) noted that in most developing countries the impact of these conferences has not gone beyond the media noise about the protocols of the events. Not much has been done beyond the rhetoric and enunciations that are generated during such conferences. Even at the local, states (provinces) and national levels, where they were aimed at gingering responsible environmental behaviours, they have turned out to be more of ceremonials like annual tree-planting campaigns and World Environment Day Celebrations. Appreciable efforts have not been made in the process of popularizing tree planting culture and in 
entrenching environmental safety consciousness in the citizenry.

Umukoro (2011), in 'Beginning of the End?' reports how the residents of Beebe town in Arkansas, USA, woke up on the first day of 2011 to discover thousands of blackbirds 'littering their backyards, streets and walk ways' (1999). He further reports how Kayode Yemitan, acting Head, Department of Pharmacology, Lagos State University, Lagos, has explained it as the outcome of climate change, warning that Nigeria should brace up for its own experience. Yemitan is further reported to have added that the accumulation of green house gases 'released majorly via industrial activities ... have been pointed out by scientists as the chief cause of global warming or climate change'(1999). The same report cites Akinbode Oluwafemi, of the Environmental Rights Action/Friends of the Earth, Nigeria, as stating that

one thing is clear, the only thing that could have been killing birds midair is as a result of some chemicals that have been injected into the atmosphere through human industrial activities.(1992)

$\mathrm{He}$ also cites the corrosion of roofs in Nigeria's Niger Delta region as evidence that the chemicals in the atmosphere are 'endangering the living mammals up there (in the sky)' (1992).

The problem of climate change is one of the fall-outs of environmental degradation. The Wikipedia (2010) defines climate change as:

a long term change in the statistical distribution of weather patterns over periods of time that range from decades to millions of years. It may be a change in the average weather conditions or a change in the distribution of weather events with respect to an average, for example, greater or fewer extreme weather events. Climate change may be limited to a specific region or may occur across the whole earth.

It could rightly be said that climate change is a product of numerous acts of environmental irresponsibility by man. It is an outcome of man's unfriendly treatment of the environment and the careless consumption and utilization of the facilities of nature, which has hardened into a ticking bomb about to explode, if nothing is done urgently to dissuade humanity from careless consumptions and usages. According to Oyebanjo (2010) climate change is made possible by the increase in the atmospheric concentration of Green House Gases ( $\mathrm{GHG}$ ) such as Carbon iv oxide $\left(\mathrm{CO}_{2}\right)$, Nitrous Oxide $\left(\mathrm{NO}_{2}\right)$, Methane $\left(\mathrm{CH}_{4}\right)$, Hydroflourcarbon (HFC), Pefluocarbon (PFC), and Sulfourhexaflouride (SF6). All these gases absorb terrestrial radiations.

There has been some debate as to the human contribution to climate change. Some argue that the problems are entirely natural- an act of God, having no human contribution and would therefore demand no human effort in the process of controlling it. To such school of thought, it could be God's visitation on the sins of mankind or a mere happenstance that will correct itself as God deems fit. But scientific explanations have cast aspersions on such explanations, and have rightly viewed the occurrence for what it is: a result of the careless habits of man that can only be ameliorated by man through God's guidance.

EduGreen (2000) holds that what the world is more worried about is that changes that are occurring today have been sped up because of man's activities. It also mentions other factors responsible for climate change as 'continental shifts, volcanoes, ocean currents, the earth's tilt, and comets and meteorites'. But it also lists human causes as industrialization and the production of greenhouse gases.

\section{Climate Change and Africa}

It is erroneous to hold the view that since Africa is not as industrialized as America and Europe, it needs not worry about the adverse effect of climate change. It is a bitter irony that Africa which contributes least of all continents to climate change, will probably suffer most from its consequences. It sounds like a case of the neighbour's stew causing breathing problems to other neighbours. It may not be entirely so. For even though Africa 
does not experience the level of industrialization that could be seen in America, Europe and some parts of Asia, some of the habits of some native African communities are in themselves great contributions to global warming and climate change.

In many African communities today for example, a farmland can only be good enough for planting after the bush has been burnt. It is possible to see great pockets of smoke emitting from African farmlands in the early part of the planting season. And some of such bush burning exercises sometimes backfire to the extent that houses and public institutions are sometimes destroyed through the straying action of such fires, as the bush burners themselves have no knowledge of modern fire-fighting techniques. Apart from bush burning, the great oil flaring going on Nigeria's Niger- Delta and some other African oil producing locations, are also contributions to global warming.

The Nigerian government once set a dateline on which oil-producing companies should stop gas flaring for 2008 (NCA, 2003), but that dateline has long past and up to the time of this writing, gas is still seriously and brazenly flared in the Niger- Delta without any declared sanctions. No new dateline has been set and no known effort is made to enforce the 'no-flaring' ban except for Vision 2020 (FGN, 2009). Besides, the nation looses great revenue as a result of this reckless action of its oil-producing companies.

Oyebanjo (2010) and NCA, 2003 stressed that though Nigeria's figure in terms of tonne of carbon/person/year as been put at 0.1 for 2001 the nation's environmental observance seem to be too poor. Other researchers, Earthlab (2007) and UNDP (2006) hold that the burning and clearing of tropical forest is a major source of greenhouse gas emissions. It accounts for roughly 16 percent of total gas emissions, more than all of the world's cars, trucks, ships, trains and planes combined. It is now generally recognised that it will be impossible to achieve any of the needed targets for mitigating climate change without significantly curbing the clearing and burning of tropical forest.
African roads are filled with cars that ooze greenhouse gases with reckless abandon. This writer notes that in his years of initiation into urbanisation, one learnt that vehicles with great smoking propensity were banned from plying the roads. But after many years of living in the urban centres, one has hardly ever heard of, nor seen anyone charged with the offence of plying the roads with such publicinconveniencing vehicles. Africa is beset with a reckless procreation habit that unwittingly increases the population thereby causing a great strain on the environment. High population has caused a great strain on land resources making people cultivate on communal reserves and erosion-prone sites (Ernest et al., 2010). People now indulge in activities like excavation of sand on erosionprone sites and slopes of streams.

Population growth has been cited as one of the causes of the stress on the environment (UNDP, 2006, NDES, 2000 and Edugreen, 2007). Edugreen (2007) for instance, asserted that because the land area available for agriculture is limited (and in fact, is usually shrinking as a result of ecological degradation), high-yielding varieties of crop are being grown to increase agricultural output from a given area of land. However, such high-yielding varieties of crops as noted by (Ekong et al., 2007) require large quantities of fertilizers, and more fertilizers mean more emissions of nitrous oxide, both from the field into which it is put and the fertilizer industry that makes it.

Many Africans cities are very poor in refuse disposal. Sometimes, the public gutters are so stuffed with refuse that rain water finds it difficult to find directed courses to go through, thereby finding paths for itself into roads and sometimes human homes. Most urban dwellers after waiting in vain for public refuse disposal vans, burn their wastes, releasing carbon gases into the atmosphere and compounding the problems of the environment.

Unfortunately, Africa is very poor in technology. Apart from the Republic of South Africa, with some appreciable level of technological development, most African countries are very poor in technological 
usages. The continent, though not rated as high as the others in acts that have contributed to climate change, stands a great risk of being most affected by an onslaught arising from climate change. Others could do one or two things in reaction to a disaster in order to save its citizens which Africa may not be capable of doing. Rather than contribute to an aggravation of the situation, Africa should be at the forefront in terms of environmental advocacy, as it does not possess the technology to take care of its citizens, even in the interim, in case of disaster. This paper therefore aimed at filling this gap by proposing an environmental communication method using the theatre for development whereby this message can be carried to all parts of Africa and indeed the entire world.

\section{Utilization of Theatre for Development in Communicating the Problem of Climate Change}

The theatre for development also known as community theatre is the ultimate in the arts utilization process. It arises out of development communication with the sole intention of giving back the theatre to the people for them to use in communicating among themselves, and with others, discussing and proffering suggestive means of creating better situations for human thrive and continuity. According to Goran Hedebro (1982), one of the major questions in development communication studies today concerns how communication can be organised so as to increase participation, achieve self-reliance, promote equity, and close communication gaps.

A close observation of the mode of operation of the formal media-radio, television, film and print media, reveal a glaring lack of feedback, which is very important in the communication process. Zakes (1993) one of the leading African voices in the theatre communication process reports of a growing concern among communication researchers that existing media systems have failed to serve the needs of development in Africa. The failure is due mostly to the undemocratic structures of the media institutions.
The theatre for development makes provision for the communal creation of the story to be performed, the acting of the story by the people themselves, the employment of improvisational creation of the dialogue by the actors and actresses, the performance of the rehearsed play before a live audience, discussions on the problems put forward through the play and a communal agreement to implement the agreed provisions. These inherent provisions make the medium the most democratic of the media of communication open to man. Moreover, the theatre for development methodology according to Zakes (1993) is not centralised like the technological media, and is capable of integrating indigenous and popular systems of communication that already exist in the rural areas. It has appropriate technology, since all it needs is human resources, which are plentiful in the villages. In an earlier theatre for development project in Ikot Ayan Itam in Nigeria (Nda, 2007) made use of Ibibio folksongs by pupils of the local primary school in passing messages of environmental safer/ best practices to the people, before the main play by the people of the community.

\section{Organization and Planning}

The proposal used in this study is based on (Nda, 2007) where the community theatre project was successfully used to create awareness on the state of the environment in Ikot Ayan Itam, Itu Local Government Area, Akwa Ibom State, Nigeria. A community theatre project should be well-planned before execution. The project could be undertaken by a non-governmental organization, a performing group or a performance-related department in an institution of higher learning.

\section{Consultations with the Community}

After the target community has been chosen, and the personnel chosen as well, the team has to establish contact with the community. The first stage of the consultation should be with the leadership of the village. Where the village community also has a caretaker committee in addition to the village head, it would be expedient to consult both. It will be after meeting with these persons that the team can fix a date for the meeting with the entire community. 


\section{Meeting with the Community}

During the meeting with the community, the team leader or the project leader has to clearly state the aim of the project. The community must be told what the project will demand of them. A volunteer performance group could be raised out of this initial meeting and another day fixed for the assemblage of these volunteers on a day not very far from the initial meeting. The project leader should tell the community what he has observed as the major climate change and governance problems of the community.

\section{Meeting with the volunteer performance group}

The first meeting with the village volunteer performance group is very crucial to the project. The project leader has to repeat the goal of project and the processes it is expected to go through. He would set the pace for the creation of the scenario or allow the group to handle the entire scenario setting. The set scenario should embody the facts about the community's peculiar and general climatic and political problems. The environmental consultant has to be present to ensure that the facts as they will be used in the scenario are correct. The team leader has to be vigilant to ensure that issues that are not in keeping with public decency and references to communal clashes as well as aspersions on other communities are entirely kept out of the production.

\section{Scripting}

That meeting should discuss the scenario of the production. It would be best if the production adopts an improvisational approach. There should be no script. The dialogue should be dependent on the improvisational ability of the actors and actresses. Where the actors and actresses do not have the appropriate words to carry the facts of the play, there should be a resort to the usage of near-expressions. For instance, in Ibibio ethnic nationality of Nigeria, and in Ibibio language, there is no direct translation for words like 'environment, climate, ozone layer', etc and short expressions in the language that resembles environment, is capable of meaning 'surrounding'. But the use of expressions that explain them are capable of presenting nearly-same meanings when employed in the production dialogue.

The play should have a straight storyline with very few sub-plots, so as not to confuse the audience. The plot should be based on cause-to-effect contrivance (which) can ensure an enfolding of dramatic action (Nda: 2010). We recommend that the plot of the play should be allowed to unfold gradually, and that there should be a monumental conflict that creates a 'bang effect' which reverberates throughout the play.

\section{Casting}

Although some theatre for development programmes have used outside actors and actresses, it is best for the process to make use of actors and actresses from the community as a means of ensuring communal ownership of the product. A project of this nature needs to be owned by the people to be believed, and its findings implemented. That is the hallmark of a development play production of this nature. It could be found out that among the volunteers could be persons who have had experiences in acting in schools and churches. In a communal casting process, persons would be given roles based on their previous roles in some past performance. Africa is a highly artistic continent whose rituals and ceremonies of the traditional state are regularly performed.

\section{Rehearsals}

After the scenario of the play has been set and the casting successfully done, the production now has to enter into the rehearsals stage. An improvisational work might not need more than three to four weeks of rehearsals. Each rehearsal period should not be overstretched more than three to four hours. In an earlier work, this writer (Nda: 2007) warns that

The management of the attention span of amateur actors who are more or less local volunteers demands levelheadedness from whoever is directing the production. The rehearsals period should not be stretched beyond reasonable duration... in an integrative production where there is a full-length play, a dance-drama and a choral performance, the director could then 
rehearse separately until a few days before public performance.

The rehearsals should not be a dictatorial affair between the director and the cast, as it happens in many professional theatres. The director should mix persuasion and assertiveness. Heffner (1973) holds that a good director should be 'a good manager, teacher and leader ...his job is not merely to interpret a play but also handle people, induce them to work together'. Yells, curses, and screams, mannerisms associated with most directors must be kept off.

Venue

The choice of the venue would determine whether the production will be staged in a proscenium, a two-sided audience seated theatre, a thrust or three-quarter arena or a pure arena. In the traditional performance setting, Africans are used to performances where both the audience completely surround the dancers and drummers as in most noninstitutional male/female dance troupes or the three quarter arena/thrust stage where the drummers sit at one end of the arena with the performers in front of them in a thrust-like large orchestra pit. But the modern African performance system seems to have introduced a new venue where most of the performances are done on the proscenium or picture-frame stage. This is a carry-over from the early church concerts, school concerts and village youth club recreational performances through which the profession of theatre crept into most African nations. This writer does not want to prescribe a venue for the climate change/political awareness campaign. Where the director decides to use an arena or threequarter arena setting, he has to direct the play in such a way that the audience members on the sides of the stage are not cheated. He has to balance his sightlines in such a way that the audience gets the message of the play.

\section{Date of Performance}

Traditional and semi-traditional societies in Africa have well-known calendars with important market days. Such societies are known to be careful in the choice of days for occasions that would demand community participation. The project leader should bear this in mind while fixing the date for the public performance. He should do this in partnership with the leadership of the community. It should be kept away from days of the community market and should not be allowed to clash with important ceremonies like the burial of an important indigene, etc.

\section{Diction}

The performance should be based on the language that the people would popularly understand. Some communities are good in the speaking and understanding of pidgin English. Where the local language or dialect is spoken by the entire community, it should be employed.

\section{Use of Technical Elements}

Some persons have suggested that community theatre performances should be devoid of costumes and other mis-un-scene elements like lighting. It should be noted that the African traditional performances are great sights in colour and spectacle. African masquerades and performances are always gorgeously costumed. Therefore to take a performance to a village, without costumes could be seen as something unserious, which would hardly attract attention.

Concerning lighting, these writers are of the opinion that it should only be kept off where the performance is taking place in a village square and in the daytime. But where the performance is taking place in an in-door venue, bringing in some form of lighting would intensify the illumination for good sighting and would also procure some added aesthetic value to the performance.

\section{The performance}

The performance proper should start with brief comments by the project leader. In his opening comments, the project leader should inform the audience to hold themselves ready to participate in a frank discussion on the issues of climate change and poor governance. Where there are features like choral and dance performance as side shows, there should precede the drama performance.

\section{Discussion Session}

The discussion segment is a major democratic feature of the theatre for development event. The discussion session 
should be moderated by the project leader. Although people should be given the freedom to discuss the issues in focus, political utterances and unfair remarks against groups and individuals, should be overruled. The various segments of the society: chiefs, men, women, young men and even matured children should be allowed to air their views on the issues at stake.

\section{Monitoring}

After successfully staging the production with a well-organized after-performance discussion, a communiqué should be produced and read for the people to adopt. It is this communique that should be monitored to measure the level of compliance. It should last as long as the group is able to finance. Where a deviation is observed, the group is free to take it up with the leaders and stakeholders in the community.

\section{Conclusion}

The foregoing has been a treatise on a practicable model on the utilization of the theatre for development methodology in communicating the perils of climate change and environmental deterioration in the African continent. It has been based on a related case study previously conducted in a local community in Africa. Its successful implementation, which has emboldened the setting out of the modalities in this paper, point to the fact that with the provision of an enabling environment, through funding and support, it is possible to implement a wellplanned process of employing the medium of theatre for development in communicating and mobilizing for a change from the attitudes that cause climate change and environmental degradation in the African society.

\section{References}

Edugreen (2007), Making environmental learning fun for the young, causes of climate change; accessed online on http://edugreen.ten.res.in/explore/climate/chan ge/causes/html on 28/10/2011

Earthlab (2007), "calculate your carbon footprint" Global warming and carbon footprint explained, earthlab foundation, accessed online on $28 / 10 / 2011$ at http://www.conservation.org/learn/climate/pages/o verview.aspx?

Ekong, F., Ebong, S.O., Ndaeyo, N, and Otu, (2007), Land use, Land cover change and Rice Production in the Niger Delta: Example from Ini Local Government Area. International Journal of Agriculture, Food production and Environment, 4 (1-4), 65-75.

Heffner, H. C. (1973), Modern Theatre Practice. New York: Meredith Corporation

Hedebro, G. (1982), Communication and Social Change in Developing Nations. Ames: The lowa University United Press

Nda, U. (2010), The Theatre and Environmental Conservation. Saarbrucken, Deutschland: Lambert Academic Publishing

Nda, U. (2007), 'Proffering a Drama-based Model for Environmental Sustainability Development' In:

Eds. Petra Kupers and Gwen Robertson Community Performance London and New York: Routledge

Niger Delta Environmental Survey (NDES) (2000), Niger Delta Development

Priorities and Action Plan, phase II report, vol. 2. Nigeria Country Anaysis (NCA) Brief (2003), Environmental Issues, accessed online:http://www.eid.doe.gov/cabs/nigenv.html on 23 , Oct 2011

Njungbwen, E. and Ekong, F. (2009), “An Assessment of Urban Growth in Uyo Using Remote Sensing Techniques" Journal of Environmental Design, 4(1\&2), 88-97.

Oyebanjo, I. (2010), "Climate change, what Nigeria must do" NBF News; at http://www.nigeriabestforum.com/blog/?p=33770 on $28 / 10 / 2011$

Paehler, H.K. (2007), "Nigeria in the dilemma of climate change", Adenauer-Shiftung-Nigeria office publication series, country's report accessed online on 26/11/2010 at http://www.kas.de/nigeria/en/publications/11468 Umukoro, A. (2011), Beginning of the End? Tell Magazine of January 24, 2011. Published by Tell Communications Limited, Lagos. pp. 24

UNDP (2006), Niger Delta Human Development Report, UN House, Abuja, Nigeria in South Africa', In: Critical Arts Vol. 2 No. 1, 1981.

Zed Books Ltd London. 